\title{
Evaluation of the impact of orthognathic surgery on quality of life
}

\section{Paola Fernanda Cotait de Lucas CORSO(a) \\ Fábio Augusto Coelho de OLIVEIRA(a) Delson João da COSTA ${ }^{(b)}$ \\ Leandro Eduardo KLUPPEL(b) \\ Nelson Luis Barbosa REBELLATO(c) \\ Rafaela SCARIOT(d)}

(a) Universidade Federal do Paraná - UFPR, School of Dentistry, Department of Oral and Maxillofacial Surgery, Curitiba, PR, Brazil.

(b) Universidade Estadual de Campinas UNICAMP, School of Odontology of Piracicaba, Piracicaba, SP, Brazil.

(c) Universidade Estadual de Campinas - UNICAMP, College of Dentistry, Piracicaba, SP, Brazil.

(d) Pontifícia Universidade Católica do Paraná - PUC PR, School of Dentistry, Department of Stomatology, Curitiba, PR, Brazil.

Declaration of Interests: The authors certify that they have no commercial or associative interest that represents a conflict of interest in connection with the manuscript.

Corresponding Author:

Paola Fernanda Cotait de Lucas Corso

E-mail:paolafcorso@gmail.com

DOI: 10.1590/1807-3107BOR-2016.vol30.0004

Submitted: Mar 13, 2015

Accepted for publication: Jun 24, 2015

Last revision: Sep 03, 2015
Abstract: Dental treatment and surgery is a well-established method of correcting dentofacial deformities, and such treatment has an impact on the quality of life of individuals. The objective of this study was to evaluate the effect of orthognathic surgery on the quality of life of patients receiving treatment at the Universidade Federal do Paraná - UFPR. Clinical data were evaluated for the control group, and a quality-of-life evaluation questionnaire was completed [Oral Health Impact Profile (OHIP-14)]. For the case group, the same data were gathered along with information regarding their dentofacial deformity. The OHIP-14 questionnaire was also completed at three distinct stages of the experiment. The median age in the control group was 23.5 years. In the case group, the predominant gender was female, and the mean age of patients was 29.4 years. There was a statistically significant association between gender and OHIP-14 ( $p<0.001)$. No such association was observed between age and OHIP-14 scores $(p=0.616)$. In the control group the OHIP-14 median score was 11.5. In the case group, the average OHIP-14 score at was 18 at T0, 21 at T1, and 8 at T2. The results demonstrated a statistically significant association between the three time stages at which OHIP-14 was analyzed ( $p<0.001)$. There was a smaller reduction in the negative impact for transversal deformities of the jaw when compared with other deformities. Orthognathic surgery led to a reduction in the negative effects on the quality of life of patients.

Keywords: Orthognathic Surgery; Dentofacial Deformities; Quality of Life.

\section{Introduction}

In the last 20 years, health status indicators have been increasingly used to assess the quality of life of patients to enable us to understand them as a whole, including the physical and behavioral aspects. Physical appearance has a significant impact on many aspects of life, and the psychological implications of this treatment deserve the attention of professionals involved in the field. ${ }^{1}$ Research criteria are no longer limited to death rate or growth rate; they instead focus more on the subjective well-being of the patient. ${ }^{2,3}$ This increased interest has been seen in relation to many health conditions that are not necessarily fatal but can cause considerable physical, social, and psychological dysfunction. ${ }^{4}$

Dentofacial deformities have a major negative social impact because of its association with esthetic and functional limitations. These can be drastically modified using orthognathic surgery. A combination 
of orthodontic therapy and orthognathic surgery is a well-established treatment method to correct moderate as well as serious dentofacial deformities. ${ }^{5}$ The prime objective of this surgery is to correct the facial skeleton so as to facilitate malocclusion orthodontic therapy. This justifies the increasing number of studies focusing on the quality of life as an important indicator of how the patient will react to treatment. ${ }^{6,7}$

Several studies have demonstrated an improvement in the quality of life following dental treatment and orthognathic surgery. ${ }^{8,9,10,11,12}$

"The Oral Health Impact Profile" (OHIP) was developed by Slade and Spencer ${ }^{13}$ in Australia in 1994, and the OHIP-14, a shorter version, was published by Slade in 1997. The OHIP evaluates the impact of dental problems on the physical, psychological, and social aspects of day-to-day life. It has been tested, developed, and accepted as being valid, precise, and reliable. ${ }^{13,14,15}$ This tool helps us to examine the expectations of individuals in relation to their health. Currently, it is used in a number of countries and effectively captures the perception of the individual in relation to quality of life associated with dental disorders. ${ }^{16}$ The categories are grouped into seven subsets, as follows: functional limitation, physical suffering, physical discomfort, physical deficiency, physical incapacity, social incapacity, and deficiency. ${ }^{14,17}$

The OHIP is used also as a research tool in various countries. According to Oliveira and Nadanovsky, ${ }_{1}^{18}$ Latin countries had no tool equivalent to the OHIP until 2005, and as a result, the authors undertook transcultural validation of this tool as used in Brazil. The study evaluated the impact of tooth pain on the quality of life of 504 pregnant patients, and the outcome suggested that the Brazilian version of the OHIP-14 allowed satisfactory psychometric evaluation, similar to the original OHIP.

Montero et al. ${ }^{19}$ in 2011 recognized the OHIP-14 as one of the most reliable indicators of quality of life in relation to oral health.

The objective of the present study was to evaluate the quality of life of patients receiving treatment at the Oral and Maxillofacial Surgery and Traumatology Center at Universidade Federal do Paraná - UFPR between August 2010 and June 2011.

\section{Methodology}

This study included 30 patients undergoing dental surgery to correct dentofacial deformities between August 2010 and June 2011 at the Oral and Maxillofacial Surgery and Traumatology Center at Universidade Federal do Paraná - UFPR. The control group consisted of patients not suffering from any dentofacial deformities. The study was approved by the Ethics Committee for Research in Health Science at UFPR (reference number CEP/SD: 1046.171.10.1). The patients included in the study were from both genders and were older than 16 years of age. Patients who discontinued treatment, cancelled appointments for reasons not connected to the study itself, or failed to appear for postoperative control sessions were excluded from the study.

For the control group, the researcher completed a form containing information specific to the subject of the study. Gender and age at the time of evaluation were recorded. For the case group, the same data were collected along with information regarding their dentofacial deformity. The resident responsible for the patient selected one of the following deformities: (a) anterior-posterior excess of the jaw, (b) vertical excess of the jaw, (c) anterior-posterior excess of the mandible, (d) anterior-posterior deficiency of the jaw, (e) transverse deficiency of the jaw, (f) vertical deficiency of the jaw, $(\mathrm{g})$ anterior-posterior deficiency of the mandible, (h) anterior open bite, or (i) mandibular laterognatism.

These deformities were grouped for analysis into DEF. 0 (Transversal Deficiency of the Jaw), DEF. 1 (AP Deficiency of the Mandible), DEF. 2 (Vertical Deformities), DEF. 3 (AP Deficiency of the Jaw/AP Excess of the Jaw), and DEF. 4 (Other Deformities). The researcher completed the form for fields such as gender, age, and type(s) of deformity(s). Thereafter, a simplified, self-applicable Brazilian version of the OHIP-14 was completed in three stages: 1 week before surgery (T0), 1 month following surgery (T1), and 3 months following surgery (T2). The control group completed the OHIP-14 at only one stage of the study to determine a parameter for evaluating the negative perception of patients in $\mathrm{T} 0$.

There are specific predetermined weights attributed to each response in the OHIP-14. The response options 
are never (0), rarely (1), sometimes (2), often (3), and always (4). Scores range from 0 to 56 points. Higher scores indicate a greater negative impact while lower scores represent greater positive impact in all treatment phases.

The data collected from the clinical profile forms and patient questionnaires were cataloged in Microsoft Excel 2007 for Windows XP ${ }^{\circledR}$. After completing the spreadsheet, the data were analyzed using the Statistical Package for Social Sciences-version 20.0; SPSS Inc. Chicago, USA). The association between variables was examined using the Mann-Whitney test (gender and OHIP-14), Spearman Rank Correlation Coefficient (age and OHIP/discrepancy), Friedman test (T0, T1, and T2 comparisons), and Kruskal-Wallis test (type of deformity and OHIP-14).

\section{Results}

The control group had 60 patients, of which 48 $(80 \%)$ were female and $12(20 \%)$ were male (Table 1$)$. The case group had 30 patients, of which $24(80 \%)$ were female and $6(20 \%)$ were male. The mean age of the subjects was 23.5 years in the control group and $29.4( \pm 9.3)$ in the case group. There was no statistically significant association observed between age and OHIP-14 scores ( $\left.p=0.616, r_{s}=0.1-95 \% C I\right)$.

Female patients had a greater negative impact at T0 $(p=0.008), \mathrm{T} 1(\mathrm{p}=0.038)$, and T2 $(\mathrm{p}=0.025)$.

The OHIP-14 total scores varied between 0 and 49 , with an average score of 11.5 points in the control group. The mean values at $\mathrm{T} 0, \mathrm{~T} 1$, and $\mathrm{T} 2$ are given in Table 1. An increase of $56.52 \%$ was observed in cases at $\mathrm{T} 0$ when compared with controls. We also observed a tendency of scores to decline from $\mathrm{T} 0$ to $\mathrm{T} 2$, and increase at $\mathrm{T} 1$. For these differences, positive values indicate an increase in the OHIP-14 score (poor quality of life) and negative values indicate a reduction in the OHIP-14 score (improved quality of life). Table 2 and Figure show the comparison of all scores of OHIP-14 at different times. Statistical significance was observed for all scores $(p<0.001)$.

With respect to the type of deformity, DEF 0,1 , and 3 formed $20 \%$ of the sample ( $n=6$ each), DEF 2 formed $26.7 \%(n=8)$, and DEF 4 formed $13.3 \%(n=4)$. $\mathrm{T} 1$ mean values were seen to increase in relation to $\mathrm{T} 2$ in DEF 0, 1, 2, and 3. Moreover, all groups showed a significant reduction in $\mathrm{T} 2$ averages in comparison to T0. In the group with transverse deficiencies of the jaw, a smaller reduction was observed at $\mathrm{T} 2$ in relation to $\mathrm{T} 0$, when compared with the other groups. However, we found no statistically significant association between the type of deformity and OHIP-14 scores at all times $(p>0.05)$. The complete results obtained are given in Table 3.

As the number of cases undergoing "Maxillary Advancement" was small it was not possible to statistically compare the type of surgery (movements) and the impact on each patient.

We observed an association between the amount of discrepancy in millimeters and T0 and T2 $(p=0.016$, $\left.r_{s}=0.4\right)$. This suggests that greater preoperative dentofacial deformities exhibited a more positive impact at $\mathrm{T} 2$.

There were no complications observed during and after surgery in the selected cases, thus making it impossible to examine the association between complications and the scores of questionnaires. Paresthesia appeared to be the most common complaint among patients after T2.

\section{Discussion}

There were some limitations in this study including the fact that patients were not evaluated by an objective test, and the scores were based mostly on the subjectivity of answers. We also faced great

Table 1. Control Group profile.

\begin{tabular}{lcc} 
& \multicolumn{1}{c}{ Age } & OHIP-14 \\
\cline { 2 - 3 } & Median (Min-Max) & Median (Min-Max) \\
\hline Female & $23(18-52)$ & $13(0-47)$ \\
Male & $24.5(19-52)$ & $3(0-21)$ \\
\hline
\end{tabular}

Table 2. The complete scores for each evaluation time.

\begin{tabular}{lcc}
\hline OHIP-14 & Median (Min-Max) & p-value \\
\hline T0 & $18(4-49)$ & - \\
T1 & $21(8-42)$ & - \\
T2 & $8(0-31)$ & - \\
T1-T0 & $4.5(-41-29)$ & $<0.001$ \\
T2-T0 & $-9.5(-44-7)$ & $<0.001$ \\
T2-T1 & $-12.5(-28-9)$ & $<0.001$ \\
\hline
\end{tabular}




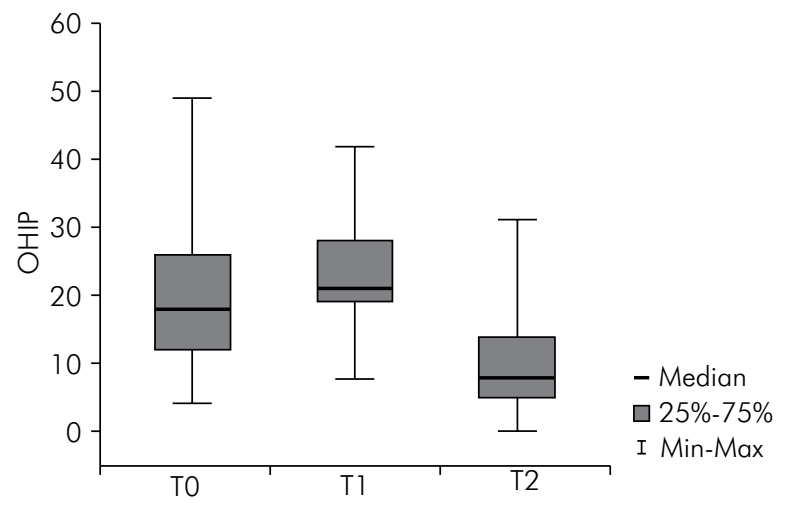

Figure. Minimum and maximum scores simulating the median line seen at each separate time period.

difficulty in monitoring patients as those that exhibited improvement in clinical conditions postoperatively often did not return. Additionally, as our service is a reference for the healthcare system in Paraná state patients often come from other cities, making it difficult for them to return.

A majority of the studies investigating orthognathic surgery included mainly female patients. These studies reported that females exhibited an increase in self-esteem and a reduction of symptoms of depression following orthognathic surgery. Male patients, however, did not show these alterations. ${ }^{18,20,21,22}$ Kiyak et al. ${ }^{23}$ reported that a significant percentage of women (53\%) and men (41\%) stated esthetics as the main reason for seeking treatment. In another study, the authors concluded that, irrespective of gender, patients demonstrated a greater positive impact. ${ }^{11,19}$

In our study, an association between the female gender and a reduction in negative impact upon quality of life was observed. This was in agreement with the previous study. Female predominance can be explained by the fact that these patients demonstrated a lower perception of quality of life in relation to dentofacial deformities (T0 average values) (24) when compared to male patients (9). This was also observed in patients who did not present dentofacial deformity, with our control group exhibiting an OHIP-14 median value of 13 in females and 3 in males.

Montero et al..$^{19}$ used the OHIP-14 to conclude that patients older than 45 years, irrespective of gender, demonstrated greater negative impact on quality of life and less satisfaction with their oral health. Given that in this study, the sample group was made up of young adults (average age 27.5 years), there was no statistical association observed between age and OHIP-14. There is a tendency among younger people to seek orthognathic surgery in greater numbers as they find themselves at a stage in life where there is greater social interaction and opportunities. A study by Silva et al., ${ }^{24}$ reported that improved selfesteem was associated with better perception of social relationship 6 months after surgery.

Based on the results at $\mathrm{T} 0$ for the case group, it appears that patients with dental deformities presented a pre-existing negative perception regarding their quality of life related to oral health to a greater extent than patients without any deformities. The presence of dentofacial deformities associated with the process of dental decompensation justified this negative perception. The decompensation phase increases the discrepancy between the deterioration of the dental arches and the patient's facial appearance, thus making the deformity more evident and esthetically less favorable.

One month after orthognathic surgery (T1), this perception was seen to deteriorate further. During this period, patients experienced edema, pain, masticatory difficulty, and limited opening of the mouth. These postoperative symptoms had a greater negative impact. This decrease in quality of life in the immediate postoperative period has also been reported previously. ${ }^{25}$

Table 3. Comparison of the OHIP-14 values in the three times of the patients with dentofacial deformities (case group).

\begin{tabular}{ccccccc}
\hline & DEF. 0 & DEF. 1 & DEF. 2 & DEF. 3 & DEF. 4 & p-value \\
\cline { 2 - 5 } & Median (Min-Max) & Median (Min-Max) & Median (Min-Max) & Median (Min-Max) & Median (Min-Max) & \\
\hline T0 & $17(04-32)$ & $18(05-34)$ & $24(10-28)$ & $24(09-35)$ & $17(06-49)$ & 0.904 \\
T1 & $21(09-32)$ & $20(15-26)$ & $27(13-42)$ & $27(14-35)$ & $11(08-28)$ & 0.378 \\
T2 & $12(01-31)$ & $06(04-12)$ & $09(00-18)$ & $09(05-17)$ & $04(03-05)$ & 0.294 \\
\hline
\end{tabular}


However, 3 months after orthognathic surgery (T2), patients showed a major positive change in the perception of their own quality of life, and a reduction in the negative impact was observed, apparent from the considerable reduction in T2 average scores compared to T0. In this phase, patients were found to have recovered and were satisfied with their state of health (a dynamic state of complete physical, mental, spiritual, and social well-being - OMS 2010), making it possible to understand the patient's expectations from the treatment. This agrees with previous studies that report improvements in quality of life following orthognathic surgery. ${ }^{9,25,26}$

We found an increase in $\mathrm{T} 1$ averages compared to T0 in DEF 0, 1, 2, and 3. In DEF 4, there was a reduction in $\mathrm{T} 1$ averages in relation to $\mathrm{T} 0$. This group was made up of patients with anterior open bite and mandibular laterognatism. These deformities are more easily noticed by the patient as they can be identified from the frontal view, unlike other deformities that are only visible from the side. This explains the rapid reduction in negative impact just 1 month after surgery.

In all groups, irrespective of deformity, there was a decrease in $\mathrm{T} 2$ averages in relation to $\mathrm{T} 0$. This suggests that patients show a positive increase in quality of life 3 months after orthognathic surgery, irrespective of the type of deformity operated on. Few studies correlate deformities with improvement in quality of life. However, one study conducted in 2008 evaluated the self-esteem of Angle's class III patients about to undergo orthognathic surgery. ${ }^{21}$ The results showed that following surgery, positive changes occurred in patients who had presented excessive anteroposterior positioning of the mandible or anteroposterior deficiency of the maxilla.

It should be stressed that the current study shows a lesser reduction of the negative impact of transverse deformities of the jaw compared to other deformities. This can be explained by the fact that patients, after 3 months of treatment, are still using expander braces, and a considerable diastema between the incisors still remains. Furthermore, the correction of this deformity does not lead to immediate major positive changes, either esthetically or in terms of masticatory function. Therefore, it does not lead to a greater perception of improved quality of life.

The quality of life of patients who participated in the study was found to have improved following treatment by orthognathic surgery, confirming the findings of other studies. ${ }^{9,10,11,21,22,26,27}$

\section{Conclusion}

The negative impact on quality of life is greater in individuals who present dentofacial deformity than in those who do not.

The female gender was predominant in the sample group. The perception of quality of life associated with dentofacial deformity was poorer in women.

In the case group, no association was observed between OHIP and age.

A majority of the patients undergoing orthognathic surgery exhibited a transitory negative increase in the immediate postoperative phase.

According to the OHIP-14 evaluation, the quality of life improved considerably in patients 3 months after the operation.

There was an improvement in the quality of life after orthognathic surgery for all groups of dentofacial deformities, particularly vertical deformities and anteroposterior deficiency of the maxilla/anteroposterior excess of the mandible.

There was a lesser reduction of negative impact for transverse jaw deformities when compared with other deformities. 


\section{References}

1. Macgregor FC. Facial disfigurement:problems and management of social interaction and implications for mental health. Aesthetic Plast Surg 1990;14(4):249-57. doi:10.1007/BF01578358

2. Kiyak HA, Reichmuth M. Body image issues in dental medicine. In: Cash TF, Pruzinsky T, editors. Body image: a handbook of theory, research and clinical practice. New York: Guilford; 2002. p. 342-50.

3. Kressin N, Spiro AIII, Bosse R, Garcia R, Kazis L. Assessing oral health-related quality of life:findings from the normative aging study. Med Care. 1996;34:416-27. doi:10.1097/00005650-199605000-00004

4. Allen PF. Assessment of oral health related quality of life. Health Qual Life Outcomes. 2003;1(1):40-8. doi:10.1186/1477-7525-1-40

5. Proffit WR, Turvey TA, Phillips C. The hierarchy of stability and predictability in orthognathic surgery with rigid fixation:an update and extension. Head Face Med. 2007;3(1):21-22. doi:10.1186/1746-160X-3-21

6. Lazaridou-Terzoudi T, Kiyak HA, Moore R, Athanasiou AE, Melsen B. Long-term assessment of psychologic outcomes of orthognathic surgery. J Oral Maxillofac Surg. 2003;61(5):545-52. doi:10.1053/joms.2003.50107

7. Alves MC, Abla LE, Santos RA, Ferreira LM. Quality of life and self-esteem outcomes following rhytidoplasty. Ann Plast Surg. 2005;54(5):511-4. doi:10.1097/01.sap.0000155274.59248.57

8. Bennett ME, Phillips CL. Assessment of health-related quality of life for patients with severe skeletal disharmony: a review of the issues. Int J Adult Orthod Orthognath Surg. 1999;14(1):65-75.

9. Hugo B, Becker S, Witt E. Assessment of the combined orthodontic- surgical treatment from the patients' point of view: a longitudinal study. J Orofac Orthop 1996;57:88-101. doi:10.1007/BF02190482

10. Hunt OT, Johnston CD, Hepper PG, Burden DJ. The psychosocial impact of orthognathic surgery:a systematic review. Am J Orthod Dentofacial Orthop. 2001;120(5):490-6. doi:10.1067/mod.2001.118402

11. Rustemeyer J, Gregersen J. Quality of life in orthognathic surgery:post-surgical improvements in aesthetics and self-confidence. J Craniomaxillofac Surg. 2012;40(5):400-4. doi:10.1016/j.jcms.2011.07.009

12. Miguel JAM, Palomares NB, Feu D. Life-quality of orthognathic surgery patients:The search for an integral diagnosis. Dental Press J Orthod. 2014;19(1):123-37. doi:10.1590/2176-9451.19.1.123-137.sar

13. Slade GD, Spencer AJ. Development and evaluation of the Oral Health Impact Profile. Community Dent Health. 1994;11(1):3-11.

14. Slade GD. Derivation and validation of a short-form oral health impact profile. Community Dent Oral Epidemiol. 1997;25(4):284-90. doi:10.1111/j.1600-0528.1997.tb00941.x
15. Slade GD, Strauss RP, Atchinson KA, Kressin NR, Locker D, Reisine ST. Conference summary: assessing oral health outcomes-measuring health status and quality and life. Community Dent Health. 1998;15:3-7.

16. Gonçalves JR, Wassall T, Vieira S, Ramalho SA, Flório FM. The impact of dental health in the life quality between men and women. Rev Gaúcha Odontol. 2004;52(4):240-2.

17. Slade GD. The oral health impact profile (OHIP). In: Slade GD, editor. Measuring oral health and quality of life. Chapel Hill, (NC): University of North Carolina; 1997. p. 93-104.

18. Oliveira BH, Nadanovsky P. Psychometric properties of the Brazilian version of the Oral Health Impact Profile: short form. Community Dent Oral Epidemiol. 2005;33(4):307-14. doi:10.1111/j.1600-0528.2005.00225.x

19. Montero J, Yarte JM, Bravo M, López-Valverde A. Oral health-related quality of life of a consecutive sample of Spanish dental patients. Med Oral Patol Oral Cir Bucal. 2011;16(6):e810-5.

20. Siow KK, Ong ST, Lian CB, Ngeow WC. Satisfaction of orthognathic surgical patients in a Malaysian population. J Oral Sci. 2002;44(3-4):165-71. doi:10.2334/josnusd.44.165

21. Nicodemo D, Pereira MD, Ferreira LM. Self-esteem and depression in patients presenting angle class III malocclusion submitted for orthognathic surgery. Med Oral Patol Oral Cir Bucal. 2008;13(1):e48-51.

22. Esperão PT, Oliveira BH, Almeida MA, Kiyak HA, Miguel JA. Oral health-related quality of life in orthognathic surgery patients. Am J Orthod Dentofacial Orthop. 2010;137(6):790-5. doi:10.1016/j.ajodo.2008.08.031

23. Kiyak HA, Hohl T, Sherrick P, West RA, McNeill RW, Bucher F. Sex differences in motives for and outcomes of orthognathic surgery. J Oral Surg. 1981;39(10):757-64.

24. Silva ACA, Carvalho RAS, Santos TS, Rocha NS, Gomes AC, Silva EDO. Evaluation of life quality of patients submitted to orthognathic surgery. Dental Press J Orthod. 2013;18(5):107-14. doi:10.1590/S2176-94512013000500018

25. Choi WS, LeeS, Mcgrath C,Samman N. Change in quality of life after combined orthodontic-surgical treatment of dentofacial deformities. Oral Surg Oral Med Oral Pathol Oral Radiol Endod. 2010;109(1):46-51. doi:10.1016/j.tripleo.2009.08.019

26. Motegi E, Hatch JP, Rugh JD, Yamaguchi H. Health-related quality of life and psychosocial function 5 years after orthognathic surgery. Am J Orthod Dentofacial Orthop. 2003;124(2):138-43. doi:10.1016/S0889-5406(03)00391-3

27. Ballon A, Laudemann K, Sader R, Landes CA. Patients' preoperative expectations and postoperative satisfaction of dysgnathic patients operated on with resorbable osteosyntheses. J Craniofac Surg. 2011;22(2):730-4. doi:10.1097/SCS.0b013e318207b700 